\title{
Cerebral and systemic endothelial dysfunction in migraine: Current knowledge and perspective
}

\author{
I Made Oka Adnyana, Valentina Tjandra Dewi
Department of Neurology, Faculty of Medicine,
Udayana University/Sanglah General Hospital, Bali, Indonesia
}

\begin{abstract}
Migraine still causes a high rate of disability and is reported to increase the risk of cardiovascular and cerebrovascular diseases. Endothelial dysfunction is considered to be one of the underlying mechanisms linking migraine and vascular disorders. Investigation of endothelial function in migraine includes a variety of examinations including biomarkers and ultrasonography-based studies. Several proposed biomarkers for endothelial dysfunction are endothelial progenitor cells (EPCs), von Willebrand factor (VWF), nitric oxide (NO), tissue-type plasminogen activator antigen (tPA antigen), C-reactive protein (CRP), endothelin-1 (ET-1), and vascular endothelial growth factor (VEGF). Brachial flow-mediated dilatation (FMD) is quite commonly used to reflect systemic endothelial dysfunction, while cerebral endothelial function can be assessed using breath holding index (BHI) on transcranial Doppler (TCD). The results of most studies in migraine sufferers indicate that endothelial dysfunction is found locally in the cerebral circulation, especially at the posterior circulation, while evidence for endothelial dysfunction in the systemic circulation remains controversial.
\end{abstract}

Keywords: biomarkers, dysfunction, endothelial, migraine

\section{INTRODUCTION}

Migraine is one of the primary headache conditions that cause a high burden for patients, families, and society [1]. Migraine is ranked as the $19^{\text {th }}$ highest cause of disability and is the $12^{\text {th }}$ leading cause of women living with a disability [2]. Various studies revealed there are many comorbidities of migraine comprising myocardial infarction, asthma, systemic lupus erythematosus, epilepsy, stroke, and several psychiatric conditions $[1,3,4]$. Migraine has been established as one of the risk factors for cardiovascular disease (CV). Meta-analysis studies showed that migraine with aura (MA) and migraine without aura (MO) was associated with ischemic stroke with greater risk in the $<45$-year-old age group, women, and oral contraceptive users [5]. The risk of ischemic stroke is also known to be higher in MA than in MO. MA is also identified as a risk factor for deep white matter lesions in the brain, sub-tentorial white matter lesions, and stroke-like posterior circulation areas [6].

Endothelial dysfunction or activation are presumed to have important roles in migraine pathophysiology and its relationship with vascular disorders $[4,7]$. However, several studies concerning systemic or local endothelial dysfunction in migraineurs showed conflicting results. Endothelial dysfunction is characterized by reduction of vasodilators bioavailability and disturbance of vascular reactivity. Endothelial dysfunction will have various effects including vascular inflammatory processes and increased blood coagulability [8]. Biological markers examination, as well as ultrasound-based studies as evidence of endothelial dysfunction and activation in migraineurs, will be discussed in this literature review. 


\section{BIOMARKERS OF SYSTEMIC CIRCULATION ENDOTHELIALFUNCTIONINMIGRAINEURS}

\section{Endothelial progenitor cells (EPCs)}

It is well-known that migraine increases the risk of cardiovascular and cerebrovascular diseases not thoroughly explained by traditional risk factors. Biological connections between migraine and the increased risk of cardiovascular abnormalities are still under investigation. The amount of circulating EPCs is a biomarker representing vascular function where decreasing number of EPCs is associated with higher risk of cardiovascular diseases. The EPCs contribute in maintaining endothelial integrity by replacing non-viable mature endothelial cells, thus act as cellular resources $[7,9,10]$. In patients with cardiovascular disease or stroke presumed harboring atherosclerosis due to the loss of endothelial repair ability, the number of EPCs is lower and may predict the disease severity and mortality $[7,11]$.

Lee et al. in 2008 conducted a study to determine EPCs abnormality and its role in migraine patients [7]. The study result was the number and function of EPCs are decreased in patients with migraine, indicating EPCs might be the connecting basis between migraine and cardiovascular disease risk. Multiple linear regression model identified decreased migratory capacity and increased cellular senescence of EPCs only in MO and MA groups compared to EPCs in tension-type headache (TTH) group or normal subject. Chronic inflammatory conditions resulting from neurogenic inflammation considered to have a potential role in reducing the number and function of EPCs in migraineurs. This may explain the more pronounced decrease of EPCs in MA because the cortical spreading depression (CSD) process during MA upregulates various species coding for inflammatory genes, including cyclooxygenase- 2 , TNF- $\beta$, IL-1 $\beta$, galanin, and metalloproteinase-9 [7].

Rodriguez et al. in 2012 also published their study on EPCs. Samples for EPCs examination were taken from the peripheral blood during the interictal and migraine attack period [12]. The study showed that patients with migraine had a lower number of EPCs than controls ( $<<0.0001)$. EPCs also decreased further during migraine attacks ( $p<0.05)$ and with migraine evolution. Their study included healthy subjects as controls, where- as Lee et al. [7] compared EPCs count between migraine and TTH group. Rodriguez et al. also excluded patients with traditional vascular risk factors and other variables that may affect vascular integrity, so it is expected that low EPCs count in the study are indeed the result of migraine-related pathophysiological mechanisms compared to the consequences of other conditions related to endothelial dysfunction [12].

Oterino et al. in 2012 conducted a case-control study regarding EPCs subtypes to examine endothelial activation and endothelial dysfunction in migraine based on its expression to E-selectin. Total EPCs were examined, defined as CD34 +1 $\mathrm{KDR}+$ cells and EPC colony-forming units (CFUs). The study identified "early" EPCs as CD62E - EPCs and "late" EPCs as CD62E +, as markers of endothelial damage. The study results indicated that there was no difference in the total number of CFUs between the study groups. The mean total number of CD34 + / KDR + and "early" EPCs did not differ significantly between study groups. However, the mean "late" EPCs were lower in the control group than in migraine patients, even after adjusting for plasma VEGF levels and other confounding factors. Linear regression showed "late" EPCs as a significant predictor of controls compared to migraine. No differences in results were observed between MA and MO in the study. Oterino et al. concluded that based on this study CD62E + EPCs could be a potential marker to indicate vascular damage in migraineurs [13].

EPCs gradually lose their progenitor properties and begin to express endothelial markers such as VE-cadherin, E-selectin, endothelial nitric oxide synthase, and von Willebrand factor in the systemic circulation $[13,14]$. After the occurrence of vascular injury, there is evidence that EPCs temporarily mobilize and increase its accumulation from bone marrow to form CFUs (CD133 +) whose ability is dependent on chronic vascular pathology [15]. The interpretation of EPC levels should be carried out with caution in the context of a combined process of acute vascular ischemia and chronic vascular injury.

Oterino et al. in their study defined phenotype $\mathrm{CD} 34+$ (hematopoietic stem) / KDR + (endothelial stem) EPCs as subtypes of EPCs that were not mobilized from bone marrow, most of which were derived from multipotent CD34 + stem cells circu- 
lating at the site of vascular injury. A circulating $\mathrm{CD} 34+$ / KDR + cell count can serve as a marker of vascular injury [13]. On the other hand, the CD62E marker is present on endothelial microparticles after endothelial activation. The CD62E identifies more mature EPCs that can be associated with potential endothelial damage. After adjusting for vascular risk factors, only CD62E + EPCs counts remained significantly lower in the control group, suggesting that migraine (independent of their subtype) itself is a vascular risk factor. These findings indicate that chronic migraine patients have higher endothelial turnover rates than controls and persistent endothelial activation $[13,16]$.

\section{Von Willebrand factor (vWF) activity}

One of the impacts of endothelial dysfunction is hypercoagulability. vWF has been widely accepted as a marker of endothelial dysfunction in plasma, which activates the platelet glycoprotein IIb/ IIIa receptor thereby causing platelet adhesion and aggregation [17]. These procoagulant proteins are known to be associated with major cardiovascular risk factors [18]. In one of the previous studies, it was found that migraine patients with stroke history had higher vWF antigen levels than migraine patients without previous stroke history [19].

Tietjen et al. published a study in 2009 regarding biological markers of endothelial activation in young women with migraine, one of which was a coagulation test examining vWF activity [8]. Study subjects included women aged 18-50 years with and without migraines without any previous cardiovascular disease. Compared with controls, women with migraines had adjusted odds ratios (ORs) for increased vWF activity of 6.51 for MA and 4.59 for MO. Within the migraine group, vWF activity correlated significantly with the tissue-type plasminogen activator antigen and nitrate/nitrite. These results support the findings of mean vWF activity values in migraine patients from 2 previous studies $[19,20]$. Tietjen et al. also found increased vWF activity was associated with ACE deletion genotype (DD), especially when combined with the methylenetetrahydrofolate reductase thiamine genotype (TT) [21]. Those genotypes are associated with endothelial dysfunction and MA [22,23].

\section{C-reactive protein (CRP)}

Endothelial dysfunction also results in the occurrence of vascular inflammation. This inflammatory condition has been hypothesized to be an important part of acute migraine pathogenesis [24]. A study conducted by Tietjen et al., comparing migraine patients and controls, found an increase in ORs to high-sensitivity CRP (hs-CRP) by 7.99 for MA and 2.63 for MO [8]. Their study concluded that there was an increase in hs-CRP in migraine patients, with a stronger association with MA than MO. Hs-CRP is a nonspecific marker of inflammation that increases endothelial expression of matrix metalloproteinase (MMP) [25]. There is a minimal correlation between hs-CRP and headache frequency, although a causal relationship has not been elucidated. The association of CRP with migraine has only been demonstrated in 2 small case-control studies and a large prospective cohort of women $>45$ years $[8]$.

\section{Tissue-type plasminogen activator antigen (tPA antigen)}

Tietjen et al. also evaluated the fibrinolysis profile by measuring levels of tissue-type plasminogen activator antigen (t-PA antigen) in young adult female subjects with and without migraine, who had no history of cardiovascular disease. Within the migraine group, vWF activity correlated with tissue-type plasminogen activator antigen $(p=0.035)$ [8]. Tietjen et al. found increased plasma t-PA antigen levels in migraine sufferers compared to controls, reflecting decreased fibrinolysis levels. A case-control study in 17 people with MO showed decreased t-PA levels [26]. A population-based case-control study in women 15-44 years, showed increased plasma t-PA antigen as an independent marker of increased stroke risk [27].

In a cross-sectional study by Vanmolkot et al. which compared subjects with migraine and without migraine history, it was found that substance $\mathrm{P}$ infusion into the brachial artery caused an increased t-PA release, but t-PA release in the two groups did not differ significantly. This raises doubts regarding the existence of endothelial dysfunction in the forearm resistance vessels of migraine patients. The study had several limitations including the small sample size that can be due to 
procedure invasiveness and even though studies using forearm already an adequate model to assess endothelial function, their clinical relevance appears to be greatest when performed on coronary and cerebrovascular vessels. This is because the vascular tissue of the forearm is less susceptible to atherosclerosis and thrombosis [28].

\section{Nitric oxide (NO)}

Vascular resistance and blood flow are regulated by a dynamic balance of vasodilator and vasoconstrictor factors. The most important vasodilator is NO but its synthesis can be impaired in the presence of oxidative stress [29,30]. Oxidative stress is a common cause of endothelial dysfunction, it is associated with vasoconstriction, increased inflammation, activation of the coagulation system, and indicates interaction between endothelial dysfunction and vascular smooth muscle [3]. Vascular reactivity to NO was significantly lower in migraineurs [29].

Endothelial dysfunction decreases vasodilator bioavailability and impairs vascular reactivity with one of the biomarkers is decrease synthesis of bradykinin-mediated endothelial nitric oxide. A study conducted by Tietjen et al. showed decrease concentration of $\mathrm{NO}$ stable metabolites in urine during the interictal period in patients with migraine compared to controls [8]. vWF activity also correlated with nitrates/nitrites in the migraine group. There have only been a few studies in the literature on nitrite/nitrate concentrations in migraine. In one recent study on migraineurs during the interictal period, there was no difference between blood nitrates/nitrites compared with controls [31]. There was also another study that showed higher interictal nitrate/nitrite concentration than control [32]. However, Bianchi et al. found that the concentration of NO metabolites was lower in migraineurs [26]. When compared with the study by Tietjen et al. [8], these other studies had smaller sample sizes, used different study methods, included males on their subjects, and few multivariate analyses $[26,31,32]$.

\section{Endothelin-1 (ET-1)}

Migraine is thought to be an "endotheliopathy" in which the vascular endothelium regulates vari- ous vascular functions [28]. In response to a specific stimulus, endothelial cells secrete locally active vasodilators, including the vasodilator nitric oxide (NO) and the vasoconstrictor endothelin-1 (ET-1). Several observational studies have demonstrated abnormal endothelial function in migraine patients, including an increase in the number of anti-endothelial cell antibodies that can induce endothelial damage [10] and an increase in plasma ET-1 levels [33,34]. Hamed et al. in their study also detected an increase in ET-1 levels in migraine sufferers [35]. ET-1 is associated with vasoconstriction where its increase can be a marker of endothelial injury associated with the production of superoxide in the vasculature. In animal studies with mice, ET-1 induced cortical spreading depression (CSD) [4,36].

\section{Vascular endothelial growth factor (VEGF)}

Rodriguez et al. studied endothelial function with biochemical and ultrasonographic markers and their association with EPCs in migraine patients [12]. One of the analyses carried out is the VEGF level. The results showed that VEGF levels in migraineurs were higher than controls $(p<0.05)$. The potential role of VEGF in migraine is not well understood. VEGF constitutes proangiogenic factors and mediates vasodilation, this leads to extravasation of plasma proteins and increases the risk of migraine. VEGF can also promote EPC release [37]. Rodriguez et al. found a decrease in EPC and an increase in VEGF in migraine sufferers as a compensatory response. The correlation mechanism between VEGF and migraine is not yet known and requires further investigation [12].

VEGF examination in migraine patients was also performed by Oterino et al, where the researchers studied the EPCs subtypes and also analyzed the plasma CGRP and VEGF levels. EPCs as angiogenic cells express 3 surface markers (CD133, CD34, and VEGF receptor-2) which are early functional angioblasts. Oterino et al. showed that plasma VEGF levels were inversely correlated with EPCs $(p=0.022)$ especially with "early" EPCs. There was no difference between VEGF and CGRP levels in plasma between the migraine and control groups in their study [13]. 


\section{ULTRASONOGRAPHY-BASED STUDY ON SYSTEMIC AND CEREBRAL ENDOTHELIAL FUNCTION IN MIGRAINEURS}

\section{Flow mediated dilation (FMD)}

FMD analysis of the dominant brachial artery is widely conducted to reflect systemic endothelial function in migraineurs. A study published by Rodriguez et al. showed that there was no change in FMD during the interictal or ictal period in migraineurs compared to controls [12]. The FMD test uses a high-resolution B-mode ultrasound device with a $7.5 \mathrm{MHz}$ linear transducer which is carried out according to the International Brachial Artery Reactivity Task Force and the guidelines of the Working Group of the European Society of Hypertension. The test was performed on the dominant brachial artery with FMD expressed as a percentage increase of arterial diameter from baseline $[12,38]$. Similar results were also obtained from a study conducted by Perko et al., where FMD investigations were carried out to reflect systemic endothelial function in migraine patients without comorbidities. This study concludes that systemic endothelial function is not disturbed in migraine patients without comorbidities, both MA and MO [39].

Several previous FMD studies on migraine during the interictal period have shown contradictory results. In contrast to the two studies presented above, de Hoon and Vanmolkot et al. found disruption of systemic vascular reactivity $[40,41]$. Yetkin et al. also suggested that migraine may be a local manifestation of systemic vascular abnormalities [42]. Further studies with larger sample sizes, the use of vasoactive substances, and simultaneous studies of the intracranial circulation are needed to confirm the research results.

\section{Breath holding index on transcranial Doppler study}

Recent studies of biological markers and non-invasive examinations of systemic endothelial function in migraineurs still suggest controversial results $[39,43]$. The resume of these studies concludes that migraine is unlikely a systemic vasculopathy with suspicion only cerebral endothelial dysfunction contributes to vascular morbidity. Brachial artery FMD is already used extensively as non-invasive studies to assess systemic endothelial function, while validated markers of cerebral endothelial function are not yet available. Carbon dioxide-mediated vasomotor reactivity (VMR) is considered to represent the cerebral endothelial function. The vasodilation response to $\mathrm{CO}_{2}$ is nitric oxide-mediated through the endothelial Nitric Oxide Synthase pathway so that cerebral VMR examination towards $\mathrm{CO} 2$ is expected to evaluate endothelial function [44]. Breath-holding $(\mathrm{BH})$ as a vasodilatory stimulus has been validated as comparable to $95 \% \mathrm{CO} 2$ inhalation in clinical practice $[44,45]$.

A study by Rajan et al. showed that the mean $\mathrm{BHI}$ of migraineurs was significantly lower in the posterior cerebral arteries and basilar arteries, but there were no different results for the middle cerebral arteries when compared to controls. The FMD examination in their study showed no significant difference between the mean brachial FMD of controls compared to migraine sufferers. The study concluded migraineurs had only endothelial dysfunction isolated in the posterior cerebral circulation but not in the systemic circulation. The reasons for the disruption of endothelial function limited to the posterior arterial circulation are not well understood. Based on the findings of Rajan et $a l$, infarction in the posterior circulation in migraine patients is thought to be the result of a direct disturbance of endothelial function than due to atherosclerosis-related embolism. Longitudinal and clinical studies correlated with MRI results are needed to support this evidence clinically [44].

\section{CONCLUSIONS}

Endothelial dysfunction is thought to be causally related to the pathophysiology of migraine and its association with vascular events. The results of various studies in migraine sufferers show that endothelial dysfunction is found in the cerebral circulation, especially the posterior circulation, with controversial study results against endothelial dysfunction in the systemic circulation. Evidence of isolated endothelial dysfunction in the posterior cerebral circulation is supported by the findings of BHI examination on posterior circulation TCD, while FMD results that reflect systemic endothelial function are still largely conflicting. Most of the biological markers of endothelial function in mi- 
graine sufferers showed a decrease in the number of EPCs in the circulation. The results and interpretation of other biological markers such as NO, vWF activity, CRP levels, tPA antigen, ET-1, and VEGF in migraineurs require further investigation. Appropriate comprehension and ongoing study towards cerebral and systemic endothelium

\section{REFERENCES}

1. Headache [Internet]. 1st ed. John Wiley \& Sons. Available at: https:// onlinelibrary.wiley.com/doi/abs/10.1002/9781118678961.

2. Organization WH. The World Health Report 2001: Mental Health : New Understanding, New Hope. World Health Organization; 2001.

3. Bonetti Piero O, Lerman Lilach O, Lerman A. Endothelial Dysfunction. Arterioscler Thromb Vasc Biol. 2003 Feb 1; 23(2):168-75.

4. Butt $\mathrm{JH}$, Franzmann $\mathrm{U}$, Kruuse $\mathrm{C}$. Endothelial function in migraine with aura - a systematic review. Headache. 2015 Jan;55(1):35-54.

5. Etminan M, Takkouche B, Isorna FC, Samii A. Risk of ischaemic stroke in people with migraine: systematic review and meta-analysis of observational studies. BMJ. 2005 Jan 6;330(7482):63.

6. Kruit MC, van Buchem MA, Hofman PAM, Bakkers JTN, Terwindt GM, Ferrari MD, et al. Migraine as a Risk Factor for Subclinical Brain Lesions. JAMA. 2004 Jan 28;291(4):427-34.

7. Lee ST, Chu K, Jung KH, Kim DH, Kim EH, Choe VN, et al. Decreased number and function of endothelial progenitor cells in patients with migraine. Neurology. 2008 Apr 22;70(17):1510-7.

8. Tietjen GE, Herial NA, White L, Utley C, Kosmyna JM, Khuder SA. Migraine and biomarkers of endothelial activation in young women. Stroke. 2009 Sep;40(9):2977-82.

9. Hristov M, Erl W, Weber PC. Endothelial progenitor cells: mobilization, differentiation, and homing. Arterioscler Thromb Vasc Biol. 2003 Jul 1;23(7):1185-9.

10. Gill M, Dias S, Hattori K, Rivera ML, Hicklin D, Witte L, et al. Vascular Trauma Induces Rapid but Transient Mobilization of VEGFR2+AC133+ Endothelial Precursor Cells. Circ Res. 2001 Feb 2;88(2):167-74.

11. Werner N, Kosiol S, Schiegl T, Ahlers P, Walenta K, Link A, et al. Circulating Endothelial Progenitor Cells and Cardiovascular Outcomes. N Engl J Med. 2005 Sep 8;353(10):999-1007.

12. Rodríguez-Osorio X, Sobrino T, Brea D, Martínez F, Castillo J, Leira R. Endothelial progenitor cells: A new key for endothelial dysfunction in migraine. Neurology. 2012 Jul 31;79(5):474-9.

13. Oterino A, Toriello M, Palacio E, Quintanilla VG, Ruiz-Lavilla N, Montes S, et al. Analysis of endothelial precursor cells in chronic migraine: A case-control study. Cephalalgia. 2013 Mar 1; 33(4):236-44.

14. Hristov M, Weber $\mathrm{C}$. Endothelial progenitor cells: characterization, pathophysiology, and possible clinical relevance. J Cell Mol Med. 2004;8(4):498-508.

15. Chu K, Jung KH, Lee ST, Park HK, Sinn DI, Kim JM, et al. Circulating endothelial progenitor cells as a new marker of endothelial dysfunction or repair in acute stroke. Stroke. 2008 May;39(5):1441-7.

16. Heiss C, Amabile N, Lee AC, Real WM, Schick SF, Lao D, Wong ML, Jahn S, Angeli FS, Minasi P, Springer ML, Hammond SK, Glantz SA, Grossman W, Balmes JR, Yeghiazarians Y. Brief secondhand smoke exposure depresses endothelial progenitor cells activity and endothelial function: sustained vascular injury and blunted nitric oxide production. J Am Coll Cardiol. 2008 May 6;51(18):1760-71.

17. McCrary JK, Nolasco LH, Hellums JD, Kroll MH, Turner NA, Moake $\mathrm{JL}$. Direct demonstration of radiolabeled von willebrand factor function in migraineurs are needed to further predict migraine clinically and provide a rationale for preventive action and management of migraine with vascular comorbidities.

\section{Acknowledgement}

All authors have equal parts in doing this article.

\section{Conflict of interest: none declared Financial support: none declared}

binding to platelet glycoprotein Ib and IIb-IIla in the presence of shear stress. Ann Biomed Eng. 1995 Nov 1;23(6):787-93.

18. Bongers TN, de Maat MP, van Goor ML, Bhagwanbali V, van Vliet HH, Gómez García EB, Dippel DW, Leebeek FW. High von Willebrand factor levels increase the risk of first ischemic stroke: influence of ADAMTS13, inflammation, and genetic variability. Stroke. 2006 Nov;37(11):2672-7.

19. Tietjen GE, Al-Qasmi MM, Athanas K, Dafer RM, Khuder SA. Increased von Willebrand factor in migraine. Neurology. $2001 \mathrm{Jul}$ 24;57(2):334-6.

20. Tietjen GE, Al-Qasmi MM, Athanas K, Utley C, Herial NA. Altered hemostasis in migraineurs studied with a dynamic flow system. Thromb Res. 2007 Jan 1;119(2):217-22.

21. Tietjen G, Herial N, Utley C, White L, Yerga-Woolwine S, Joe B. Association of von Willebrand Factor Activity with ACE I/D and MTHFR C677T Polymorphisms in Migrainecha. Cephalalgia. 2009 Sep 1;29(9):960-8.

22. Makris TK, Stavroulakis GA, Dafni UG, Gialeraki AE, Krespi PG, Hatzizacharias AN, et al. ACE/DD genotype is associated with hemostasis balance disturbances reflecting hypercoagulability and endothelial dysfunction in patients with untreated hypertension. $\mathrm{Am}$ Heart J. 2000 Nov 1;140(5):760-5.

23. Kowa H, Fusayasu E, ljiri T, Ishizaki K, Yasui K, Nakaso K, et al. Association of the insertion/deletion polymorphism of the angiotensin I-converting enzyme gene in patients of migraine with aura. Neurosci Lett. 2005 Feb 10;374(2):129-31.

24. Williamson DJ, Hargreaves RJ. Neurogenic inflammation in the context of migraine. Microsc Res Tech. 2001;53(3):167-78.

25. Páramo JA, Rodríguez JA, Orbe J. Vulnerable plaque versus vulnerable patient: emerging blood biomarkers for risk stratification. Endocr Metab Immune Disord Drug Targets. 2007 Sep;7(3):195-201.

26. Bianchi A, Pitari G, Amenta F, Giuliano F, Gallina M, Costa R, et al. Endothelial, haemostatic and haemorheological modifications in migraineurs. Artery. 1996 Jan 1;22(2):93-100.

27. Macko RF, Kittner SJ, Epstein A, Cox DK, Wozniak MA, Wityk RJ, et al. Elevated Tissue Plasminogen Activator Antigen and Stroke Risk. Stroke. 1999 Jan 1;30(1):7-11.

28. Vanmolkot FH, de Hoon JN. Endothelial function in migraine: a cross-sectional study. BMC Neurol. 2010 Dec 1;10(1):119.

29. Murinova N, Krashin DL, Lucas S. Vascular risk in migraineurs: interaction of endothelial and cortical excitability factors. Headache. 2014 Mar;54(3):583-90.

30. Chrissobolis S, Miller AA, Drummond GR, Kemp-Harper BK, Sobey CG. Oxidative stress and endothelial dysfunction in cerebrovascular disease. Front Biosci Landmark Ed. 2011 Jan 1;16:1733-45.

31. Silva FA, Rueda-Clausen CF, Silva SY, Zarruk JG, Guzmán JC, Morillo CA, Vesga B, Pradilla G, Flórez M, López-Jaramillo P. Endothelial function in patients with migraine during the interictal period. Headache. 2007 Jan;47(1):45-51.

32. Ciancarelli I, Tozzi-Ciancarelli M, Massimo CD, Marini C, Carolei A. Urinary Nitric Oxide Metabolites and Lipid Peroxidation By-Products in Migraine. Cephalalgia. 2003 Feb 1;23(1):39-42.

33. Gabrielli M, Santarelli L, Addolorato G, Foschi G, Cristiana DC, Gasbarrini A, et al. High Prevalence of Antiendothelial Cell Antibodies in Migraine. Headache. 2002;42(5):385-6. 
34. Gallai V, Sarchielli P, Firenze C, Trequattrini A, Paciaroni M, Usai F, et al. Endothelin 1 in migraine and tension-type headache. Acta Neurol Scand. 1994;89(1):47-55.

35. Hamed SA, Hamed EA, Ezz Eldin AM, Mahmoud NM. Vascular Risk Factors, Endothelial Function, and Carotid Thickness in Patients with Migraine: Relationship to Atherosclerosis. J Stroke Cerebrovasc Dis. 2010 Mar 1;19(2):92-103.

36. Elmarakby AA, Loomis ED, Pollock JS., Pollock DM. NADPH Oxidase Inhibition Attenuates Oxidative Stress but Not Hypertension Produced by Chronic ET-1. Hypertension. 2005 Feb 1;45(2):283-7.

37. Asahara T, Takahashi T, Masuda H, Kalka C, Chen D, Iwaguro H, et al. VEGF contributes to postnatal neovascularization by mobilizing bone marrow-derived endothelial progenitor cells. EMBO J. $1999 \mathrm{Jul}$ 15;18(14):3964-72.

38. Corretti MC, Anderson TJ, Benjamin EJ, Celermajer D, Charbonneau F, Creager MA, et al. Guidelines for the ultrasound assessment of endothelial-dependent flow-mediated vasodilation of the brachial artery. J Am Coll Cardiol. 2002 Jan 16;39(2):257-65.

39. Perko D, Pretnar-Oblak J, Sabovic M, Zvan B, Zaletel M. Endothelium-dependent vasodilatation in migraine patients. Cephalalgia. 2011 Apr 1;31(6):654-60.
40. de Hoon J, Willigers J, Troost J, Struijker-Boudier H, Van Bortel L. Cranial and Peripheral Interictal Vascular Changes in Migraine Patients. Cephalalgia. 2003 Mar 1;23(2):96-104.

41. Vanmolkot FH, Bortel LMV, Hoon JN. Altered arterial function in migraine of recent onset. Neurology. 2007 May 8;68(19):1563-70.

42. Yetkin E, Ozisik H, Ozcan C, Aksoy Y, Turhan H. Decreased endothelium-dependent vasodilatation in patients with migraine: a new aspect to vascular pathophysiology of migraine. Coron Artery Dis. 2006 Feb;17(1):29-33.

43. Vernieri F, Moro L, Altamura C, Palazzo P, Antonelli Incalzi R, Rossini PM, et al. Patients with migraine with aura have increased flow mediated dilation. BMC Neurol. 2010 Mar 10;10(1):18.

44. Rajan R, Khurana D, Lal V. Interictal cerebral and systemic endothelial dysfunction in patients with migraine: a case-control study. J Neurol Neurosurg Psychiatry. 2015 Nov 1;86(11):1253-7.

45. Ringelstein EB, Kahlscheuer B, Niggemeyer E, Otis SM. Transcranial doppler sonography: Anatomical landmarks and normal velocity values. Ultrasound Med Biol. 1990 Jan 1;16(8):745-61. 